\title{
ABORDAGEM DO ENFERMEIRO NO GRUPO EDUCATIVO COM GESTANTES CANDIDATAS À LAQUEADURA*
}

\author{
Arlete de Souza Barros ${ }^{* *}$ \\ Fátima F. M. Christóf oro ${ }^{* * *}$
}

\begin{abstract}
RESUMO: Enfon:amos neste trabalho a abordagem do enfermeiro enquanto coordenador de grupo educativo com gestantes candidatas à laqueadura. Enfatizamos a necessidade de um referencial teórico específico para trabalharmos com grupos de pacientes. Queremos evidenciar também o papel de educador inerente ao enfermeiro e a importância da sua atuação na equipe multiprofissional da área de saúde. A metodologia do grupo educativo é suscintamente descrita, na forma de um protocolo, que apresentamos como sugestão para o desenvolvimento de atividades semelhantes.
\end{abstract}

ABSTRACT: We present by means of this thesis the nurse's approaching while coordinator of the educative group whit pregnant candidates to ligature. We emphasizes the need of a especific theoric material to deal with those pacientes groups. Furthermore we would like to distach the educative task of the nurse and the importance of his performance in the multiprofissional team in the health area. The methodology of the educative group is succintly described as a protocol which we present as a suggestion for the development of the similar activities.

\section{APRESENTAÇAOO}

Há mais de vinte anos que a equipe multiprofissional ligada ao Departamento de Tocoginecologia (DTG) da Faculdade de Ciências Médicas (FCM) da Universidade Estadual de Campinas (UNICAMP) vem se precupando com o desenvolvimento de ações educativas que visem proporcionar um espaço de reflexão c discussão sobre as condições de saúde e de atendimento à mulher.

Os programas cducativos foram surgindo à medida que os profissionais perceberam a necessidade de ouviro que as mulheres tinham para falar à respeito de si próprias e de sua história de vida.

O Programa de Laqueadura. isto é, o atendimento às pacientes que solicitam esterilização cirúrgica definitiva, teve inicio ainda nas instalações da antiga Santa Casa de Campinas, prédio no centro da cidade que abrigava o DTG e os outros departamentos da FCM.
A partir de 1986, o DTG e a equipe multiprofissional passaram a prestar assistência nas novas instalações do Centro de Assistência Integral à Saúde da Mulher - CAISM/UNICAMP. Nessa ocasião, o atendimento do Programa de Laqueadura desdobrou-se entre o Hospital das Clínicas (HC) e o CAISM.

Em abril de 1988, o então diretor do DTG, convocou uma Comissão Especial para reestruturar o Programa e discutir novamente os critérios, normatizando o encaminhamento e a avaliação da solicitação da cirurgia pela paciente. Essa comissão era formada por uma enfermeira, uma psicóloga, uma assistente social e coordenada por um médico, professor do DTG/FCM/UNICAMP.

Esta Comissão baseou-se principalmente nos estudos de PINOTTI et al. (14) e referendou os critérios que já vinham sendo utilizados na prática.

Finalmente, em julho de 1988, o Programa de Laqueadura passou a ser totalmente efetivado pela

\footnotetext{
* Trabalho apresentado como tema livre no $44^{\circ}$ Congresso Brasileiro de Enfermagem. Brasília, D.F., 1992.

** Enfermeira do Serviço de Educação em Saúde/DAT - Programa de Laqueadura do Pré-Natal Normal - CAISM/UNICAMP

*** Enfermeira Supervisora/IDIVEN - Programa de Laqueadura do Pré-Natal Especializado - CAISM/UNICAMP.
} 
equipe multiprofissional do CAISM em conjunto com os docentes do DTG/FCM. (13)

O Programa de Laqueadura consiste numa série de atividades, através das quais as mulheres são atendidas quanto ao desejo da contracepção definitiva. Para atendê-la existem três comissões:

- Comissão do Programa de Laqueadura para mulheres não grávidas;

- Comissão do Programa de Laqueadura para as gestantes do pré-natal normal;

- Comissão do Programa de Laqueadura para as gestantes do pré-natal especializado;

Cada Comissão atua em equipe multiprofissional composta por: um médico (professor do DTG/FCM/ UNICAMP), uma enfermeira, uma assistente social e uma psicóloga (profissionais do CAISM).

A enfermeira atua, principalmente, em dois momentos do processo: na realização do gnupo educativo, e na comissão de avaliação do pedido para laqueadura.

Neste trabalho, abordaremos o momento do grupo educativo, enfocando fundamentalmente a metodologia utilizada na prática cotidiana de coordenação de grupos de gestantes, solicitantes de esterilização cirúrgica definitiva.

\section{INTRODUÇÃO}

Vários autores vêm se referindo à questão da esterilização feminina. BERQUÓ (2) cita que "diante das reduzidas opções e recorrendo inadvertidamente à pílula, à procura de um método eficiente, e frente a sua intolerância, só resta à mulher a laqueadura tubária." O Conselho Estadual da Condição Feminina de São Paulo, em 1986, afirma que "o ritmo de expansão da esterilização foi mais rápido entre as mulheres de nível mais baixo de instrução", e que "é bem provável que a grande maioria destas solicitações seja determinada por fatores outros que não a autonomia e a autodeterminação das mulheres, como por exemplo, as condições sócio-econômicas, a educação sexual dentro dos padrões machistas, a política de saúde...". (6)

Os estudos de PINOTTI et al. (12) recomendam que "o casal que escolhe a esterilização cinúrgica deve estar devidamente informado de todos os outros métodos alternativos de contracepção, do caráter irreversível da laqueadura e dos seus riscos, que incluem a possibilidade de arrependimento."

Por outro lado, ALMEIDA (1) considera que, na equipe de saúde, o enfermeiro deve desenvolv cr uma ação que reúna competência técnico-científica, administrativa e política, no sentido de considerar a clientela em sua realidade concreta e histórica. $\mathrm{O}$ corpo de conhecimentos a respeito do processo saúde-doença deve ser socializado dentro da equipe de trabalho, $\mathrm{c}$ para fora dela, atingindo a clientela e permitindo. desta forma, o desenvolvimento de uma consciência crítica facilitadora de mudanças tanto à nível do enfermeiro quanto dos usuários de serviços de saúde.

Entendemos aqui, equipe de saúde definida por SAN MARTIN, citado por FERNANDES ${ }^{(8)}$ como sendo "a integração das funções que descnvolvem diferentes técnicas através de um programa planificado que persegue objetivos comuns onde os profissionais atuam em igualdade de condições na fomulação e desenvolvimento do plano."

Prestar assistência à saúde da mulher $\mathrm{cm}$ cquipc multiprofissional pressupõc um espírito democrático de trabalho em grupo entre os técnicos no qual as decisões emanam da própria cquipe.

Trabalhar com grupos, scjam de profissionais ou de pacientes, exige do enfermciro conhecimentos específicos. GRINBERG et al. (10) citam NEWCOMB e faz referências a duas condições básicas do ponto de vista sociológico para a constituição dc um grupo: a primeira, diz que os participantes "compartilham dc normas acerca de algo cm particular". c a scgunda condição seria de que "o gnupo estcja formado dc indivíduos cujos papéis sociais se encontram cstrcitamente interligados". O autor continua assinalando que, do ponto de vista psicológico. além dessas duas condições, o gnupo apresenta uma união especial. uma coesão entre seus integrantcs. "Todas cssas pessoas, e cada uma delas em particular, desempenham inconscientemente, detcrminados papćis ou funçõcs em estreita ligação de interdependência "

BUSNELLO in OSÓR IO ct al. ${ }^{(4)}$ refere que "os seres humanos têm o scu destino ligado ao funcionamento de grupos e que não ć possível tcr uma visão lúcida do homem, sem ter uma visão lúcida também dos grupos humanos com o quais eles intcragem."

ZIMMERMANN ${ }^{(14)}$ salienta entre as características gerais do grupo terapêutico o fato de ser constituído pelo psicoterapcuta (coordenador) pelos pacientes (integrantes) c. cm alguns casos. um ou dois observadores. O número indicado de pacientes participantes de um grupo é de 6 a 8 , c a duração média de uma sessão $\mathrm{em}$ torno de sessenta minutos. É preferível que o local seja uma sala de tamanho médio ( 15 a $20 \mathrm{~m} 2$ ), protegida contra nuídos. decorada discreta- 
mente e contendo unicamente os móveis necessários para o funcionamento de um giupo. As cadeiras deverão ser confortáveis e todas iguais.

O método Paulo Freire apresenta contribuições para trabalho com grupos, e é segundo BRANDÃO (3) "um método de educação construído em cima da idéia de um diálogo entre educador e educando, onde há sempre partes de cada um no outro." A teoria de Paulo Freire fala de uma educação que liberta, porque contribui para a formação de uma consciência crítica, e estimula a participação responsável de cada cidadão no processo que está vivenciando, seja ele cultural, social, político ou econômico. Desta forma, segundo PAULO FREIRE (9), a educação participativa tem como finalidade criar condições de aprendizagem, mediante as quais os indivíduos que participam dos mesmos interesses e sentem as mesmas necessidades possam conhecer melhor seus problemas e sua realidade..." e continua "....a educação participativa permite que os educandos se tornem agentes de seu próprio desenvolvimento, em vez de beneficiários passivos."

LAGANÁ (1) ressalta em seus estudos que "a adequação da prática de enfermagem às necessidades de saúde da população, converge, em grande parte, para a questão educativa." Esta prática educativa deve partir das vivências pessoais do paciente/cliente e apenas guiada pelo conhecimento técnico do enfermeiro. O processo educacional reflexivo provoca conflitos que geram um repensar de modelos e padrões pré-estabelecidos.

Considerando as recomendações de $\mathrm{COCCO}$ et al. (7), que apontam principalmente para o desempenho do enfermeiro na equipe multiprofissional e sua atuação junto a clientes que buscam a laqueadura, avaliamos que seja muito importante a maneira de como atuar, e a utilização de uma metodologia própria para se trabalhar tão relevante questão da saúde da mulher.

Observa-se nos autores citados, a ênf ase na ação educativa realizada em grupo c. como marco, a metodologia utilizada no desenvolvimento do grupo.

O presente trabalho tem como objetivos:

1. evidenciar a participação do enfermeiro na discussão e ef etivação de atividades que promovam a conscientização da clientela quanto a questão da esterilização cirúrgica definitiva;

2. valorizar o trabalho do enfermciro na cquipe multiprofissional, considerando que cada profissional contribui com sua formação específica em bene- fício da realização da ação de saúde;

3. refletir, questionar e propor uma metodologia de trabalho do enfermeiro com grupos educativos para gestantes que solicitam laqueadura;

\section{METODOLOGIA DO GRUPO EDUCATIVO COM GESTANTES CANDIDATAS À LAQUEADURA}

\subsection{Aspectos Técnicos:}

As gestantes são recrutadas para o grupo de acordo com os critérios de encaminhamento do Programa de Esterilização Cirúrgica do DTG/CAISM. (13)

\section{Critérios de encaminhamento}

- idade mínima: 30 anos;

- filhos vivos: 03 (preferencialmente de ambos os sexos);

- gestante: até o $5^{\circ}$ mês de gravidez;

- indicação médica para laqueadura;

- avaliação do uso anterior de métodos anticoncepcionais.

\section{Critérios de Aprovação de Laqueadura:}

- idade mínima: 30 anos;

- paridade: $4^{\text {a }}$ gestação (atual);

- número de filhos: 03 (preferencialmente de ambos os sexos);

- estabilidade conjugal: relacionamento conjugal de pelo menos 5 anos;

- concordância expressa do cônjuge.

As gestantes são previamente agendadas para o grupo educativo do Programa de Laqueadura em número de sete a nove participantes. Esta atividade é coordenada pela enfermeira, conta com a participação da assistente social e tem, em média, uma hora e meia de duração. O local desta atividade é uma sala apropriada para se trabalhar com grupos de pacientes. $\mathrm{O}$ mobiliário é simples e conta com várias cadeiras, uma mesa, três armários, um quadro-negro e um mural. A iluminação e a ventilação são suficientes.

O material educativo utilizado na discussão é uma série de cartazes.

Os temas abordados são: anatomia efisiologiado aparelho reprodutor feminino, sexualidade da mulher, métodos anticoncepcionais em geral, ènfocando 
métodos contraceptivos definitivos: laqueadura e vasectomia.

\subsection{Aspectos do Método:}

O método utilizado para o desenvolvimento da atividade educativa com as gestantes candidatas à laqueadura, é o método participativo, incorporando aspectos básicos utilizados em grupos terapêuticos.

A atividade é iniciada com a apresentação do Programa de Laqueadura, apresentação das profissionais e das gestantes integrantes do grupo. Todas as participantes usam crachás com os nomes legíveis. A enfermeira solicita a cada gestante que durante a apresentação pessoal diga sua idade, o número de gestações e filhos que possui, os métodos anticoncepcionais que já usou e por que quer fazer a laqueadura. É feita uma discussão geral à partir dos dados apresentados.

Em seguida, é sugerido pela coordenadora conversar sobre o corpo da mulher, mais especificamente sobre os órgãos genitais extemos e intemos. A partir de então, a discussão gira em tomo da sexualidade, do prazer sexual, da relação sexual, do processo da fecundação, da gravidez e, finalmente, das maneiras possíveis de evitar uma gestação. Inclui-se, nesse momento, uma explicação sobre a salpingectomia bilateral.

As informações de aspectos biológicos são permeadas pelo conteúdo vivencial que cada gestante vai pouco a pouco colocando para o gnupo, evidenciando-se o contexto social, econômico, psicológico e político, ora ressaltado pela enfermeira ou pela assistente social, ora apontado pela própria gestante.

À medida que o grupo evolui, fica cada vez mais claro e compreensível para as integrantes, o que é a laqueadura em relação à saúde da mulher como um todo, em seus aspectos biológicos e psicossociais.

\section{APRESENTAÇÃO E DISCUSSÃO DA EXPERIÊNCIA}

O Grupo Educativo é uma atividade obrigatória do Programa de Laqueadura para as gestantes que solicitam a cirurgia. Às vezes as pacientes reclamam que, mais um comparecimento atẹ o CAISM, implica em gasto monetário com o transporte, ou ainda, que não têm com quem deixar os filhos pequenos. Em geral, temos observado em nossa prática, que a maioria das gestantes gosta da atividade e participa da discussão. Muitas agradecem ao se despedirem. Consideramos que isto acontece devido ao fato delas se sentirem respeitadas enquanto pessoas, mulheres grávidas e cidadãs. Antes de mais nada, são ouvidas e talvez, esse seja um dos poucos espaços que elas possuem no seu dia-a-dia para conversar sobre as questões ligadas à sua saúde.

Ao se iniciar o grupo educativo, todas as participantes sentam-se em círculo, cadeiras lado a lado; todas nós somos mulheres em idade reprodutiva; as pacientes, - mulheres grávidas - com uma preocupação que é a laqueadura. Essas características nos identificam, nos unem e facilitam nossa comunicação.

Ao se proceder a apresentação de cada gestante, percebe-se que as dúvidas, os medos, os questionamentos, as fantasias, as ansiedades, os tabus, os preconceitos e as informações incorretas, são comuns àquelas mulheres. Essa apresentação promove uma certa integração, diminui as tensões iniciais e assegura que nenhuma gestante fique desapercebida no grupo.

A partir dessas primeiras colocações, é iniciado um processo de aprendizagem coletiva, embasado na participação da paciente enquanto sujeito da atividade grupal.

O objetivo dessa atividade grupal é, fundamentalmente, criar condições para que as gestantes reflitam e analisem a realidade sobre a saúde da mulher, adquiram uma nova consciência crítica e transformadora que lhes permita optar ou não pela laqueadura, tomando uma decisão segura e tranqüila.

Ainda nas primeiras colocações da apresentação pessoal, evidencia-se que as mulheres, em geral, estão desinformadas, ou possuem informações incorretas sobre os métodos anticoncepcionais, fazem uso deles indevidamente e, até mesmo, com sérias contra-indicações.

Ao responderem porque querem fazer a laqueadura, a maioria delas aponta a situação sócio-econômica e cultural que as impede de ter o direito à saúde e ao número de filhos que desejariam, contrariando o expresso na $8^{\text {a }}$ Conferência Nacional de Saúde, Brasília, 1987: o direito à saúde significa a garantia, pelo Estado, de condições dignas de vida e de acesso universal e igualitário às ações e serviços de promoção, proteção e recuperação de saúde. (5)

O que as mulheres expressam é que "a vida está dura, o dinheiro é pouco e os filhos passam necessidades" ou "não tem creche e preciso trabalhar" ou ainda "não tenho condições de dar estudos aos meus filhos." Na verdade, são poucas as gestantes que na primeira justificativa dizem querer a laqueadura porque não querem mais engravidar. Tentamos, nesse momento, refletir com elas, o que é o dese jo interno 
e o desejo verbalizado sobre a laqueadura. Algumas apontam que, se as condições de vida fossem outras, não estariam pensando na contracepção definitiva.

Mas, para se falar da cirurgia é necessário falar sobre o corpo da mulher. Com o auxílio dos cartazes, vamos conversando e assegurando a horizontalidade do diálogo. Nossa linguagem técnica e específica é adequada à popular, e assim nos fazemos entender, trocando idéias sobre órgãos genitais externos e internos. Constatamos que é recomendável iniciar pelos externos, tentando fazer valer a coerência dos orifícios, canais e órgãos, seus aspectos e suas funções. Percebemos então que as mulheres não detêm esses conhecimentos, o seu próprio corpo não lhes pertence. Existem muitas dúvidas em relação ao ciclo menstrual e à fecundação. Há um sentimento de vergonha em relação aos genitais. $O$ clitóris é desconhecido ou estão não é assumido.

O prazer é dispensável ou "coisa de homem". Uma dúvida que freqüentemente aparece é "porque eu engravido se eu não sinto prazer?" ou "sou fria, não tem jeito".

Assinalamos aqui que esse gnupo educativo tem a finalidade de discutir a laqueadura, no entanto, percebe-se que a questão é bem maior, mais ampla. Trata-se da cidadania da mulher enquanto pessoa, com direito à informações básicas sobre sua saúde e ao atendimento mínimo de suas necessidade.

Observamos que os cartazes utilizados no transcorrer da atividade gnupal funcionam como elemento gerador da discussão, estimulada pelas colocações da enfermeira. Ficamos sempre atentas às perguntas $\mathrm{e}$ tentamos esclarecer dúvidas.

Ao chegarmos à discussão propriamente dita da laqueadura, perguntamos às participantes o que elas sabem à respeito da cinurgia. Na grande maioria das vezes, as gestantes têm somente a informação de que "operando, não tem mais filhos". Aos poucos vamos conversando sobre o que é a laqueadura, a técnica da cinurgia, o uso da anestesia, o tempo de internação. Tentamos passar para elas o significado da cirurgia nas trompas. À medida que as noções ficam mais claras, as gestantes continuam fazendo muitas perguntas. Os questionamentos apontados abrangem a eficácia, problemas de saúde associados e interferência, ou não, com a sexualidade da mulher.

Em geral, assinalamos para as participantes, que a cirurgia de esterilização definitiva, na maioria das vezes, não é uma cirurgia de urgência. Então não há necessidade de realizá-la impreterivelmente no pós- parto imediato.

A reflexão crítica que o gnupo promove conduz cada participante à uma nova consciência sobre a laqueadura, torna a gestante sujeito da ação, estimulando sua participação responsável no processo de escolha e tomada de decisão à favor ou não da cinurgia.

Essa conscientização pode reafirmar sua opção, ou levá-la a tomar uma outra atitude, que implicará em desistir da laqueadura, optar por outro método anticoncepcional que não seja definitivo, ou ainda, pensar mais sobre o assunto.

Algumas vezes, após o grupo, as gestantes nos comunicam que mudaram de idéia e que este não é o momento de vida adequado para a realização da ligadura tubária.

Portanto, entendemos que o grupo educativo sobre laqueadura não é somente explicar o que é a cirurgia. Implica numa postura profissional do enfermeiro cuja competência se revela pelo conhecimento técnico e pela sensibilidade ao atender as mulheres em suas necessidades de saúde.

\section{CONCLUSÕES:}

Tendo em vista o atendimento, coordenado pelo enfermeiro, do gnupo educativo com gestantes candidatas à esterilização cinúrgica definitiva do Programa de Laqueadura do DTG/CAISM/UNICAMP. concluímos que:

- o momento do grupo educativo é fundamental para que as gestantes, em conjunto, reflitam e discutam à respeito da laqueadura nos seus mais diversos aspectos: quanto à anatomia e fisiologia, sexualidade, contexto familiar, con jugal e social, além dos aspectos mais gerais de política de saúde para a população brasileira:

- a apropriação do conhecimento a respeito do seu próprio corpo, como ele é, e como funciona, é o ponto inicial da discussão sobre a laqueadura;

- a utilização do Método Paulo Freire e o conhecimento específico sobre Grupo Terapêutico são referências imprescindíveis ao enfermeiro, enquanto coordenador de grupos educativos com pacientes.

- neste trabalho apresentaremos um protocolo como sugestão para o desenvolvimento de atividades educativas semelhantes. (Anexo) 


\section{REFERÊNCIAS BIBLIOGRÁFICAS}

1. ALMEIDA, M.C.P. A formação do Enfermeiro frente à Reforma Sanitária. Cadernos de Saude Pública, Rio de Janeiro, p. 505-510, 1986

2. BERQUÓ, E. Sobre o declinio da fecundaçõa e anti-concepção em São Paulo, Campinas, Núcleo de Estudo da População - NEPO, Unicamp, 1986.

3. BRANDÃO, C.R. O que é o Método Paulo Freire, 13 ed. Coleção Primeiros Passos, São Paulo: Brasiliense, 1987.

4. BUSNELLO, D.E. Dinâmica de Grupo. In: OSÓRIO, Luiz Carlos et al. Grupoterapia Hoje, Porto Alegre, 1986.

5. CADERNOS DE SAÚDE PÚBLICA. $8^{a}$ Conferência Nacional de Saúde. Escola Nacional de Saúde Pública, Rio de Janeiro, p. 505-510, 1986.

6. CADERNOS DO CONSELHO ESTADUAL DA CONDIÇÃO FEMININA. $O$ direito de ter ou nõa ter filhos no Brasil. Edição Especial, São Paulo, 1986.

7. COCCO, M.J.M. et al. Programa de Laqueadura. Relato de Experiência com Grupo Multiprofissional. Revista Brasileira de Enfermagem, Brasilia, 41, n. 1, p. 64-8, 1988.
8. FERNANDES, J.D. Contribuição da Equipe multiprofissional nas Ações de Saúde - Mito ou Realidade? Revista Brasileira de Enfermagem, Brasilia, 34, p. 175-181, 1981.

9. FREIRE, P. Conscientização: teoria e prática da libertação: uma introdução do pensamento de Paulo Freire. 3 ed. São Paulo: Moraes, 1980.

10. GRINBERG, L. et al. Psicoterapia de Grupo, Rio de Janeiro: Forense Universitária, 1976.

11. LAGANÁ, M.T.C.A. A educação para a saúde: o cliente como su jeito de ação. Revista da Escola de Enfermagem - USP, São Paulo, 1989.

12. PINOTTI, J.A. et al. Identificação dos fatores associados à insatisfação após esterilização cirúrgica. UNICAMP/DTG/FCM, 1986.

13. RELATÓRIO DA COMISS ÃO ESPECIAL DE ESTUDOS DO PROGRAMA DE ESTERILIZAÇÃO CIRÚRGICA NO DTG/CAISM, (xerocópia), 1988.

14. ZIMMERMANN, L. Estudo sobre Psicoterapia Analitica de Grupo, São Paulo: Mestre Jou, 1971.

\section{ANEXO}

\section{PROTOCOLO DA METODOLOGIA DO GRUPO EDUCATIVO COM GESTANTES CANDIDATAS À LAQUEADURA}

(Programa de Laqueadura - DTG/CAISM/UNICAMP)

\section{Coordenação do Grupo* : Enfermeiro}

Método: educação participativa

(Segundo Método Paulo Freire)

Local: Sala apropriada e privativa

Duração: 90' (noventa minutos no máximo)

Número de Participantes: 6 a 8 gestantes (no máximo)

\section{ETAPAS:}

- participação voluntária das gestantes;

- disposição das participantes em círculo;

- utilização de crachás por todos os componentes do grupo;
- apresentação da atividade, das profissionais e das pacientes;

- utilização de uma linguagem simples, clara, compreensível e objetiva;

- atenção para a comunicação verbal e não verbal estabelecida pelas integrantes do grupo;

- transmissão de informações corretas, livres de preconceitos e tabus, respeitando-se as crenças e costumes culturais;

- utilização de material educativo adequado;

- abordagem gradativa dos temas: anatomia e fisiologia do aparelho reprodutor feminino, resposta sexual e sexualidade da mulher, o processo da fecundação, meios de contracepção, laqueadura.

* O grupo educativo do Programa de Laqueadura DTG/CAISM/UNICAMP conta com a participação de assistente social. 